\title{
Professionalism as a part of Medical Curriculum: Need of the Hour
}

\author{
${ }^{1}$ Siddharth P Dubhashi, ${ }^{2}$ GN Saxena, ${ }^{3}$ Saurabh Sharma
}

\begin{abstract}
Professionalism in medicine can be viewed as contact between the medical professional and the society. There are no established methods of teaching and valuating professionalism in the traditional medical curriculum. Inculcation of values of medical professionalism requires integration of value and behavior among faculty, non-teaching staff, postgraduate and undergraduate students. Teaching can be enhanced using experimental learning. Various methods include case-based learning, hidden curriculum, role plays, peer-assisted learning. Medical teachers act as role models for students. Assessment should foster an environment for change. There should be an effective feedback and an opportunity for continuous improvement.
\end{abstract}

Keywords: Experimental learning, Feedback, Professionalism, Role modeling.

How to cite this article: Dubhashi SP, Saxena GN, Sharma S. Professionalism as a part of Medical Curriculum: Need of the Hour. J Mahatma Gandhi Univ Med Sci Tech 2016;1(2):39-41.

\section{Source of support: Nil}

Conflict of interest: None

\section{INTRODUCTION}

Professionalism in medicine can be viewed as contact between the medical professional and the society. Numerous rules and regulations, codes of conduct govern medical professionals. However, there are no established methods of teaching and evaluating professionalism in the traditional medical curriculum. In the current era of consumer awareness and corporate practice, inclusion of professionalism as a part of the medical curriculum is need of the hour.

\section{WHAT IS PROFESSIONALISM?}

Medical Professionalism has been defined in various ways.

\footnotetext{
${ }^{1}$ Director, Professor and Head, ${ }^{2}$ Dean, Professor and Head ${ }^{3}$ Undergraduate student

${ }^{1}$ Academics and Student Affairs; Department of Surgery Mahatma Gandhi Medical College and Hospital, Jaipur Rajasthan, India

${ }^{2,3}$ Department of Medicine, Mahatma Gandhi Medical College and Hospital, Jaipur, Rajasthan, India

Corresponding Author: Siddharth P Dubhashi, A2/103 Shivranjan Towers, Someshwarwadi, Pashan, Pune, Maharashtra India, Phone: +91-9881624422, Fax: 020-25883666, e-mail: spdubhashi@gmail.com
}

The General Medical Council (UK) has described professionalism as provision of good clinical care, maintaining good medical practice, teaching and training, relationships with patients, working with colleagues, probity, and health. ${ }^{1}$ The American Board of Internal Medicine (ABIM) defines of professionalism with six components: Altruism, excellence, honor/integrity, accountability, duty, respect. ${ }^{2}$ The CANMEDS (project of Royal College of physicians and surgeons of Canada) have identified specific roles in a competent professional: medical expert, communicator, manager, collaborator, health advocate, scholar, and professional. ${ }^{3}$

In 2002, the ABIM and the European Federation of Internal Medicine brought out the Physician Charter defining professional responsibilities. ${ }^{4}$ The Charter included three fundamental principles of professionalism: Patient welfare, Patient autonomy and Social justice. Ten professional responsibilities were also defined by the Charter: Commitment to competence, confidentiality, patient relationship, honesty, access to care, distribution of finite resources, quality of care, scientific knowledge, management of conflicts of interest, responsibilities.

In 2005, the Royal College of Physicians of London Working Party on Medical Professionalism explained the concept as a set of values, relationships and behavior that underpin the public trust in doctors, with doctors being committed to the professional attributes, viz. integrity, compassion, altruism, excellence, improvement, and teamwork. ${ }^{5}$

Inculcation of values of medical professionalism requires integration of value and behavior among faculty, nonteaching staff, postgraduate and undergraduate students.

\section{Teaching Professionalism}

Professionalism is a complex entity and warrants a variety of teaching methods that need to be integrated with each learning phase of the medical curriculum. A true professional would evolve over time by a process of exploration and reflection. ${ }^{6}$ The teaching of professionalism needs to be enhanced through development and dissemination of learning models, particularly in relation to experiential learning. ${ }^{7}$ 


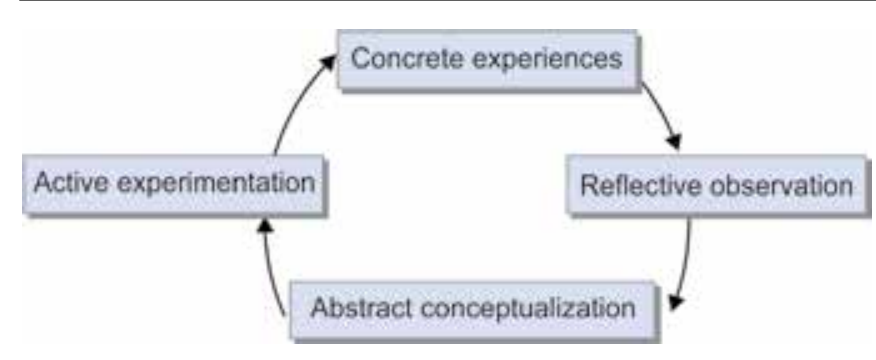

Fig. 1: Kolb's learning cycle

\section{Kolb's Learning cycle 8,9}

The Kolb's learning cycle (Fig. 1) provides effective connection between theory and practice. It helps students realize themselves, helps faculty to become reflexive teachers, thereby enriching the teaching-learning process. Concrete experience: Active participation by students.

Reflective observation: Reflection on one's own experiences. Abstract conceptualization: Student's formulation of an idea based on what he/she observed.

Active experimentation: Plan to implement the theory in a new situation.

Methods of teaching professionalism would include: Case-based learning, role plays, ward rounds, thematic movies, role modelling, mentoring through informed discussions, hidden curriculum, simulated patients, group discussions, peer-assisted learning, self-appraisals.

\section{Role Modelling}

Medical teachers act as role models for students. ${ }^{10}$ Faculty should provide an ambience conducive to an effective teaching-learning. This should include ample opportunities for performing, reflection and an element of constructive criticism. A good feedback explains not only what should have done, but why it should be done. A supportive learning environment is the key for effective role modelling.

Training in professionalism involves:

- Formulation of policy statements (acceptable behavior)

- Formative and summative evaluations

- Facilitating remediation for inappropriate behavior

- Advocating a cultural change.

Christianson et $\mathrm{al}^{11}$ advocate a patient-centered curriculum in early years of training as a way to bring about organizational cultural shift toward an outward rather than inward focus, countering the hidden curriculum and enhancing development of professionalism.

Potential threats to teaching and learning of professionalism:

- No shared definition

- No consequences for unprofessional behavior

- No recognition of exemplary behavior

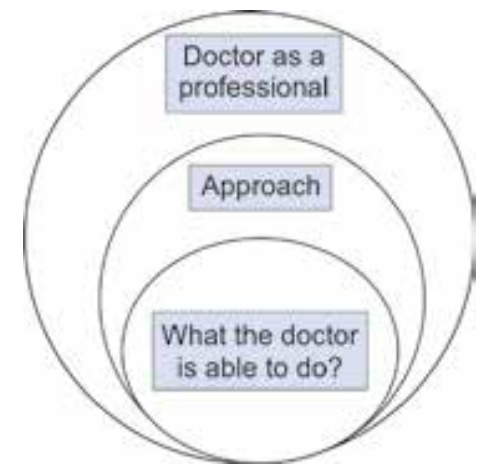

Fig. 2: Three circle framework for learning outcomes

- Reflexive not reflective thought of action

- Brief episodic interaction between faculty and trainees.

\section{Assessment of Professionalism}

Competency in professionalism involves cognitive as well as non-cognitive skills, viz. communication, collaboration and continuous improvement. ${ }^{12}$ Harden et $\mathrm{al}^{13}$ have formulated the three circle framework for learning outcomes (Fig. 2).

To be successful role performer, individuals must possess deeply internalized performance abilities which would enable them to deal with a variety of real life experiences over time.

Assessment should begin early, be conducted frequently, include many assessors who should be trained. It should foster an environment for change. Various assessment tools include: Case presentations, OSCE, Mini-CEX, Direct Observation of Procedural Skills, Portfolios, $360^{\circ}$ evaluation.

The educational portfolio is an important tool that allows links to be build up between the processes of learning and assessment and can be utilized to assess the components of integrity, honesty, and attitudes. ${ }^{14}$

\section{CONCLUSION}

Medical professionalism is a complex phenomenon. A professionalism curriculum should be formulated based on the institutional environment in which it is taught. There is an increasing awareness amongst faculty to incorporate professionalism training into the medical curriculum. Role modelling and experiential learning are effective teaching tools. Assessment strategy should employ educational portfolios with an effective feedback and an opportunity for continuous improvement.

"Mediocre teacher tells, good teacher explains, superior teacher illustrates, and exceptional teacher inspires". 


\section{REFERENCES}

1. General Medical Council. Good Medical Practice. London: General Medical Council; 2006.

2. American Board of Internal Medicine. Project Professionalism. Philadelphia: ABIM; 1995.

3. Thistlethwaite JE, Spencer J. Professionalism in Medicine. Oxford: Radcliffe Medical Press; 2008.

4. Project of ABIM Foundation, ACP-ASIM Foundation and European Federation of Internal Medicine. Medical professionalism in the new millennium: a Physician Charter. Ann Intern Med 2002;136:243-246.

5. Royal College of Physicians. Doctors in society: Medical professionalism in a changing world. Report of a Working Party of the RCP London: Royal College of Physicians; 2005.

6. Passi V, Doug M, Peile E, Thistlethwaite J, Johnson N. Developing medical professionalism in future doctors: a systematic review. Int J Med Educ 2010;1:19-29.

7. Swick HM, Szenas P, Danoff D, Whitcomb ME. Teaching professionalism in undergraduate medical education JAMA 1999;282:830-832.
8. Kolb D. Experimental learning: experience as the source of learning and development. Englewood Cliffs, New Jersey: Prentice Hall 1984.

9. Sharlanova V. Experimental learning. Trakia J of Sci 2004;2(4): 36-39.

10. Paice E, Heard S, Moss F. How important are the role models in making good doctors? BMJ 2002;325:707-710.

11. Christianson CE, McBride RB, Van RC, Olson L, Wilson HD. From traditional to patient-centered learning. Curriculum change as an intervention for changing institutional culture and promoting professionalism in undergraduate medical education. Academic Medicine 2007;82:1079-1088.

12. Kirk LM. Professionalism in Medicine: definitions and consideration for teaching. Proc (Bayl Univ Med Cent) 2007; 20:13-16.

13. Harden RM, Crosby JR, Davis MH. An introduction to outcome-based education. Medical Teacher 1999;21(2):7-14.

14. Driessen E, Van Tartwijk J, Van der Vleuten C, Wass V. Portfolio in medical education: why do they meet with mixed success? A systematic review. Med Education 2007;41:12241233. 